$3{ }^{1} \mathrm{PhD}$ research student, School of Engineering, Faculty of Engineering and Informatics, University of Bradford, Bradford, West Yorkshire, BD7 1DP, UK.

${ }^{2}$ Senior Lecturer, School of Engineering, Faculty of Engineering and Informatics, University of Bradford, Bradford, West Yorkshire, BD7 1DP, UK.

7 Bradford, West Yorkshire, BD7 1DP, UK.

* Corresponding author

Dr Mostafa Mohamed

Email: $\underline{\text { m.h.a.mohamed@bradford.ac.uk }}$

Phone: +44(0) 1274233856 


\section{Analysis of sequential active and passive arching in granular soils}

K. Aqoub, M. Mohamed and T. Sheehan

ABSTRACT: Arching in soils has received great attention for several decades due to its significance on the soil-underground structure-interaction. However, soil layers underneath such an underground structure might undergo cycles of swelling and shrinking resulting in the generation of alternating active and passive modes of soil-underground structure-interaction. Consequently, the stresses on the underground structure and adjoining regions of ground become complex. The state of stress on underground structures as a result of cycles of active and passive arching was neither explored nor systematically assessed. In the present study, comprehensive investigation was carried out to examine; i. the effects of direction of initial displacement to induce an initial active or passive arching, ii. the behaviour of subsequent arching, iii. the effect of magnitude of initial displacement on the formation of arching and iv. the influence of soil height on sequential active \& passive arching. The experimental results showed clearly that the magnitude of displacement of the yielding region significantly affects the formation of the arch and the degree of stress redistribution. Alternating the displacement of the underground inclusion exacerbated the formation of active and passive arching leading to a substantial reduction in shear resistance and stress redistribution. It is noted that the greatest loss in shear resistance occurs from the second cycle and remains virtually the same with further cycles. Sequentially alternating displacement of the underground inclusion is found to be detrimental to the formation of full active and passive arches irrespective of the burial height.

KEYWORDS: Arching of soil, Trapdoor displacement, Lateral earth pressure coefficient, Active arching, Passive arching, Sequential active and passive soil arching. 


\section{INTRODUCTION}

Underground structures such as buried conduits, tunnels, piled embankments, shelters and vertical anchors are increasingly built and utilised for prosperity of societies all over the world. It is paramount that such an underground structure is designed sustainably, efficiently and effectively. One of the major uncertainties in the design is the interaction between underground structure and surrounding soils which is dependent on the type and shape of structure, type of surrounding soils and free field stresses. Arching mechanisms play a pivotal role in the interaction between surrounding soils and underground structures/inclusions (e.g., Lee et al. 2006; Meguid et al. 2008; Costa et al. 2009; Van Eekelen 2015 \& Fattah et al. 2016). Depending upon the relative displacement between the underground structure/inclusion and adjacent soils, redistribution of stresses would occur as a result of the formation of either active or passive arching. For instance, if an underground inclusion subsides, a reduction in vertical stress occurs on the yielding area or the region of the underground inclusion in comparison with the anticipated undisturbed overburden pressure in the free field due to active arching. The relative movement between the yielding region and the adjacent less deformable regions of the ground mobilises shear stresses. The evolving shear stress tends to minimise and/or prevent the settlement of the yielding part by reducing the pressure on this yielding region of the inclusion as well as increasing the pressure on the relatively stationary soil regions (Terzaghi 1943). In contrast, if an underground inclusion is stiffer than the adjacent soil regions, an increase in the loads/vertical stress occurs on the underground inclusion alongside a reduction in the stresses on the adjacent soil regions (passive arching) (Iglesia et al. 2014). The additional loads due to passive mode may lead to damage of the buried structures if care is not undertaken (Clark 1971).

Several experimental, analytical and numerical investigations were conducted with different perspectives including developing analytical equations (e.g.; Terzaghi 1943; Iglesia et al. 1999; Pirapakaran and Sivakugan 2007a,b \& Cui et al. 2017), studying the shape of soil arching (e.g.; Handy 1985 \& Iglesia et al. 2014), quantifying the effect of soil type (e.g.; Stone and Muir Wood 1992; Iglesia et al. 2014; Pardo and Saez 2014 \& Wang et al. 2017) and studying the mode of arching (e.g.; 
Vardoulakis et al 1981; Koutsabeloulis and Griffith 1989; Costa et al. 2009 \& Dalvi \& Pise 2012). Studying the arching effect in granular soils was performed experimentally by Terzaghi using a trapdoor test (Terzaghi 1936). Terzaghi then proposed an analytical solution based on his trapdoor experimental results. It was assumed that the behaviour of the soil was within the plastic state. Terzaghi's equation for plane strain situation is given by Equation 1.

$$
\sigma_{v}=\frac{\gamma B}{2 k \tan \phi}\left(1-e^{-2 k \tan \phi \frac{H}{B}}\right)
$$

where; $\sigma_{v}$ is the vertical stress on the trapdoor, B is the trapdoor width, $\gamma$ is the unit weight of granular soil, $\phi$ is the friction angle of sand, $k$ is the ratio between horizontal and vertical stresses and $\mathrm{H}$ is the height of the sand bed. Later on Pirapakaran and Sivakugan (2007a, b) extended Terzaghi's solution to a 3-D situation where the vertical load was placed on a rectangular trapdoor of finite length and width $(\mathrm{L} \times \mathrm{B})$. Although Equation 1 has been widely used in calculating the stresses on yielding inclusions, it requires an accurate value for the earth pressure coefficient $(k)$ which proves to be an issue to most engineers. Terzaghi (1943) assumed that an empirical value of $k$ equals to 1.0 for practical applications whereas Krynine (1945) assumed a $k$ value higher than the value of active earth pressure based on an inclined shearing surface. Russell and Pierpoint (1997) extended Terzaghi's solution by using a square arrangement of square columns supporting the embankment and recommended the use of a $k$ value equals to 1.0 as proposed by Terzaghi (1943). Russell et al. (2003) suggested that the $k$ value is to be taken 0.50 . Recently, Potts and Zdravkovic (2008) showed that a coefficient of lateral pressure equal to unity gave comparable results to those obtained from a plane strain numerical analysis to arching over a void. Vardoulakis et al. (1981) proposed expressions for the distributions of the soil loads on the trapdoor in active and passive modes based on shear bands. The expression for active arching is consistent with Terzaghi's (1943) equation when $K=1.0$. However, the proposed equation for passive arching involves a correction factor which was proposed to be 1 1.5. Tanaka and Sakai (1993) discussed the progressive failure of the arching of granular soil and the scale effect experimentally and numerically and found that the earth pressure distribution in the experimental results was in agreement with numerical outcome. Iglesia et al. (1999); Chevalier et al. 

strain case during the trapdoor displacement and it was concluded that the soil arching goes through a series of phases e.g. initial arch, maximum arching, recovery stage and final stage. Horgan \& Sarby (2002) conducted an experimental plane strain model by using a trapdoor test for two types of granular materials and found the critical height for both soils to be located between 1.545 and 1.92 times the width between the supports. Sadrekarimi \& Abbasnejad (2008) studied the effects of soil density and trapdoor width on the arching of soil. The results showed that the ultimate stress on the trapdoor decreased as the relative density increased. The width of the trapdoor and relative density influence the formation of a stable arch.

Despite all the aforementioned studies, the focus was on investigating distinctive modes of arching e.g. either active or passive mode separately upon isolation of external environmental influences. For example, underground inclusions or structures may undergo cycles of upward and downward movement due to swelling and shrinking of expansive soil layers. Expansive soil layers that exist beneath the underground inclusions are prone to cycles of swelling and shrinking upon slight change in moisture content. This may in turn change the arching mechanism from active to passive mode or vice versa and deviate the stresses from those that were determined based on one of the two recognised arching mechanisms. The focus of this paper is to investigate experimentally using the well-developed trapdoor set-up various scenarios for the effect of sequentially alternating active and passive arching on redistribution of stresses. This study therefore aims to i) quantify the effect of a sequentially alternating arching mode on redistribution of loads exerted on underground inclusions, sequentially alternating active and passive arching, and iii) explore potential impacts for the number of alternating cycles of active and passive arching on stress reduction. The results from the comprehensive testing programme are presented and discussed hereafter. 
The testing setup used in this study is fundamentally similar to the trapdoor setup used in previous experimental studies (e.g.; Terzaghi 1936; Evans 1983; Stone 1988; Dewoolkar et al. 2007; Chevalier et al. 2008; Costa et al. 2009 \& Iglesia et al. 2014). Figure 1 shows a schematic drawing of the testing set-up. The test setup consisted of a wooden tank with the front wall made of thick Plexiglass in order to enable visual observation and measurement of the soil deformation. The utilised testing tank had a length of $700 \mathrm{~mm}$, a width of $250 \mathrm{~mm}$ and a height of $600 \mathrm{~mm}$ as shown in Figure 1 . The trapdoor with a width of $100 \mathrm{~mm}$ was centred and located at the base of the testing tank. The trapdoor itself was designed to move downward or upward at a constant rate of $1.0 \mathrm{~mm} / \mathrm{min}$ by a ball screw actuator in order to release or induce pressure on the trapdoor as a result of active and passive arching mechanisms respectively. A load cell was mounted to the base of the trapdoor to measure the applied load on the trapdoor as shown in Figure 1. In order to avoid or minimise frictional resistance and to prevent ingress of fine sand particles between the trapdoor edges and the opening side walls a fibre seal that covered all four edges of the trapdoor was used.

\section{MATERIALS}

Sand was used as a testing material in this experimental investigation. The sand utilised in this experimental study had a range of particle sizes between $410 \mu \mathrm{m}$ and $710 \mu \mathrm{m}$. The important index properties of the sand are summarized in the Table 1. According to BS EN ISO 14688-2:2004, the sand is classified as uniformly-graded medium sand. Standard Proctor compaction tests revealed that the optimum moisture content and maximum dry unit weight of the sand were $8.0 \%$ and $16.50 \mathrm{kN} / \mathrm{m}^{3}$ respectively. In order to prepare samples with uniform dry unit weight, a sand raining technique was utilised by which dry sand was dropped from a predetermined height at a constant rate. The rate of sand raining was controlled by changing the aperture size of the holes in the sand raining box base whilst the dropping height was kept constant by gradually lifting the raining box upward. The unit weight of the formed sand beds was measured at different heights to ensure its uniformity across the whole tank. Measurements were taken at three different points at each level. Table 2 illustrates 
values of measured dry unit weight taken from five preliminary tests. Data in Table 2 shows an average dry unit weight of $16.37 \pm 0.02 \mathrm{kN} / \mathrm{m}^{3}$ which was considered acceptable. The measured dry unit weight values indicate that adopting the sand raining technique resulted in preparation of dense sand beds with a dry unit weight comparable to the maximum achieved dry unit weight from the standard Proctor Compaction test.

\section{TESTING PROCEDURE AND PROGRAMME}

A sand bed was created by pouring sand particles into the testing tank through the raining box until reaching the required height. Then the surface of the sand bed was levelled off in order to avoid any discrepancy in the overburden pressure. Typically, each test was initiated by moving the trapdoor at a rate of $1.0 \mathrm{~mm} / \mathrm{min}$ until reaching a predetermined displacement e.g. $10.0 \mathrm{~mm}$. The test was then temporarily stopped and movement of the trapdoor was reversed to perform the opposite stage of arching. Loads on the trapdoor were recorded every 10 seconds. Each test was conducted to simulate 10 cycles of alternating active and passive arching.

Thirteen experiments were performed as illustrated in Table 3 in order for a deeper understanding of the behaviour of granular soil arching in sequentially alternating active and passive modes to be acquired. The first series of tests was performed on a sand bed with a thickness of $100 \mathrm{~mm}$ to investigate the formation of monotonic active and passive arching in granular soil, the results of which were used as a control. The second Seri/s included testing of two samples with a fixed sand bed thickness of $100 \mathrm{~mm}$ to study the effect of the first arching mode on the load transfer onto the inclusion as a function of sequential changes of arching mode. The third series of tests was conducted to investigate the sequential active and passive arching under different trapdoor displacements of 2 $\mathrm{mm}, 10 \mathrm{~mm}$ and $20 \mathrm{~mm}$ respectively. The last series of experiments was devoted to the effect of burial depth/sand bed thickness on the behaviour of soil arching in sequentially alternating active and passive modes. Six samples of sand beds with different thicknesses were prepared and then tested at the same displacement of $10 \mathrm{~mm}$. 


\section{RESULTS AND DISCUSSIONS}

180

181

182

183

Of note, data attained from the trapdoor experiments were presented as normalized load against normalized displacement. The normalized load on the trapdoor is determined by dividing the measured load on the trapdoor by its original value at zero displacement which is comparable to that in the free field. The normalized displacement is determined by dividing the trapdoor displacement by the width of the trapdoor. The normalisation of loads and displacements is adopted to enhance the presentation and comparison of data sets and to show clearly the percentage changes in load due to active and passive arching.

It is also important to note that the second and fourth series of testing underwent 10 cycles of movement of the trapdoor up to a displacement of $10 \mathrm{~mm}$ to simulate sequential active and passive arching. However, the third series of tests underwent 5 cycles of downward and upward movement up to displacements of $2 \mathrm{~mm}, 10 \mathrm{~mm}$ and $20 \mathrm{~mm}$. All measurements were taken every 10 seconds. Hereafter, results are presented and discussed to clearly demonstrate the effects of underground inclusion displacement and height of sand bed on the behaviour of arching of soil under sequential active and passive modes.

\subsection{Effect of sequential active and passive arching}

In this section, experiments were undertaken with a sand bed of $100 \mathrm{~mm}$ as illustrated in Table 2 .

Two experiments were conducted to ascertain the monotonic active and passive arching in granular soils. Load measurement on the trapdoor at rest conditions prior to the onset of displacement was found to be equivalent to the free field vertical stress times the area of the trapdoor. Figure 2 shows the normalised load against normalised deformation for monotonic active and passive arching. Data presented in Figure 2 show distinctive behaviour for granular soil during active and passive state. It is important to note that minimum load achieved during yielding of the underground inclusion (active arching) is $9.3 \%$ of the original at rest load and was experienced after a settlement of $1 \%$ of the inclusion width which is consistent with previous observations by Terzaghi (1943) and Iglesia et al. 

observed at a normalised displacement of $2 \%$. It is also worth noting that the drop rate in the load during active arching is almost double the rate of increase during the passive arching to reach minimum and maximum load respectively. With further displacement, a relatively stable load is experienced during active and passive modes reaching a higher normalised load of $49 \%$ and a lower normalised load of $163 \%$ during the active and passive modes respectively as showing in Figure 2 beyond a normalised displacement of $5 \%$. This is due to the soil mass having reached the critical state and soil particles being re-organised along the slip planes. The results, therefore, suggest that relying on maximum and minimum loads on the inclusion as a result of complete passive and active arching respectively seems to be unsustainable. Careful consideration would need to be taken during the design of underground inclusions, in particular when shallow granular soil cover that is equal to one width of the underground inclusion is used.

The next series of testing was conducted to investigate the effect of initial movement (yielding or rise of trapdoor) on subsequent behaviour of soil arching. Data captured for the load on the underground inclusion (trapdoor) during the initial release of pressure due to active arching or during initial compression of soil mass by passive arching are presented in Figures 3-a and b respectively. The monotonic active and passive relations presented in Figure 3 show typical behaviour comparable to those presented in Figure 2. It was recorded that prior to the onset of tests, the soil mass seemed to be at rest and the recorded load on the trapdoor was directly related to overburden pressure. However, the relationships for subsequent cycles of active and passive modes are unique and different from those recorded for the monotonic relationships. This suggests a clear dependence of the behaviour of subsequent arching on the stress history. As the underground inclusion (trapdoor) started to yield, a decreased pressure was observed due to

227 the shear resistance in the soil illustrating the development of active arching (Figure 3a). Due to the 228 initial dense packing of the sand bed with a unit weight of almost $100 \%$ of that achieved from 229 Standard Proctor Compaction test, the mass of soil above the trapdoor dilated vertically upon 
yielding of the inclusion which was recorded by the lower surface settlement rather than the

231 trapdoor displacement. A similar interpretation was made by Villard et al. (2000) in which the rate of

232 dilation was found to be higher than the trapdoor displacement causing the soil to fill the gap under

233 the arching and thus increasing the arching effect. In contrast, the adjacent soil masses on both stationary regions (left and right sides of the inclusion) would dilate horizontally preventing the soil mass above the yielding inclusion from moving downwards which resulted in lowering the pressure on the inclusion (trapdoor). This has occurred entirely due to the internal friction and interlocking of sand particles and can be represented by the angle of friction and the angle of dilation. In contrary upon rise of inclusion from a $10 \%$ yielding, passive arching started to form rapidly and gradually showed an increased load on the inclusion reaching a maximum normalised load of $193 \%$ after undergoing an upward normalised displacement of approximately $6 \%$.

The second and subsequent relationships between normalised load and normalised displacement

242 due to cycles of active and passive arching were similar resulting in intermediate but coinciding 243 paths. During second and subsequent active modes, a minimum normalised load did not appear to 244 occur, as evidenced by the data at a normalised displacement of $1 \%$, whereas the measured load at 245 the critical state was similar. The normalized vertical load at a normalized displacement of $1.0 \%$ during the second cycle was about four times greater than that which was observed at a normalized displacement of $1.0 \%$ during the first cycle, as can be seen in Figure 3-a. Similarly, Figure 3-b illustrates that the normalised loads during the second and subsequent cycles of passive mode at a normalised displacement of $2 \%$ no longer represented a peak value but were almost half of that measured during the monotonic passive resistance. Careful inspection of Figure 3 illustrates that the normalised load corresponding to $5 \%$ normalised displacement is the same during subsequent active

252 and passive modes irrespective of the initial direction of displacement. This indicates that during 253 alternating active and passive modes, the major and minor principal stress change directions based 254 on the direction of the inclusion's movement (trapdoor). To further explain the alteration of principal 255 stresses during the redistribution of stresses, the lateral earth pressure coefficient was determined 
and plotted in Figure 4 as a function of inclusion's movement for various active and passive arching

257 cycles. The value of coefficient of earth pressure was calculated by the ratio of the horizontal stress to the vertical stress which was determined from the measured load on the inclusion that is presented in Figure 3. Evans (1983) measured the horizontal stress during trapdoor tests and found that the horizontal stress remained fairly constant. It seemed therefore reasonable to assume a constant value of horizontal stress which is also consistent with earlier suggestion made by Terzaghi (1943) for the trapdoor test. The horizontal stress was then taken as the initial at rest. Of note, the initial lateral earth pressure coefficient was determined as $k_{o}=1-\sin \phi$. As a result, a $k_{o}$ value of 0.46 is used in this investigation which is within the suggested range of 0.4-0.5 by Lambe and Whatman (1969) for sand beds that were created by vertical accumulation of sand particles under no significant lateral compression during sedimentation which is precisely similar to the preparation approach adopted in this investigation.

From Figure 4, it can be seen that the coefficient of earth pressure increased with increasing the downward displacement until reaching a maximum value of 3.0 at a normalized displacement of $0.67 \%$. The increase in the coefficient of lateral earth pressure led to a significant reduction in the vertical load on the trapdoor (underground inclusion). At this stage the soil would behave as an elastic strain material mobilising the peak shear strength to provide maximum frictional resistance and hence the maximum active arching would be developed (Evans 1983).

Despite further yielding of the trapdoor, a fairly constant coefficient of lateral pressure was recorded which indicates that the rate of dilation continued but at a lower rate until reaching zero value at a normalised displacement of $5 \%$. Records of surface settlement along the centreline of the trapdoor illustrated that no surface settlement was recorded until reaching a yielding of $5 \%$ as shown in Figure 5b. Costa et al. (2009) observed significant dilation in the soil region immediately above the trapdoor at failure. A reduced $\mathrm{K}$ value resulted in an increased vertical load on the yielding inclusion which can 280 be attributed to a reduction in the angles of friction and dilation as a result of lowered shear strength of the soil. This indicates in turn a reduced arching effect. Due to the decrease in shear strength with 
increasing yielding of the inclusion, the soil would behave as a strain softening material (Evans 1983). With additional yielding of the inclusion beyond $5 \%$, the lateral coefficient of pressure reached a constant value of unity which was recommended by a number of researchers including Terzaghi (1943). Furthermore, a relatively constant load was measured on the trapdoor despite the value of normalised displacement indicating that the soil mass had reached the critical state. During this stage, most of inclusion yielding was transferred to the surface settlement as can be observed in Figure 5-c.

Reversing the direction of movement at a normalised displacement of $10 \%$ led to an increase in the measured load due to the formation of passive arching. The major principle stress was then in the vertical direction leading to a value of lateral earth coefficient of 0.25 which is close to that determined by Rankine's theory. With further cycles of active and passive mode, the coefficient of lateral earth pressure stayed relatively stable at 1.0 and 0.25 for active and passive modes respectively excluding the first $4 \%$ normalised displacement in each direction due to the instability in the soil mass as a result of dilation and contraction.

Figures $5 \mathrm{~d}$-h show pictures of the sand bed after cycles of active and passive modes. It can be seen that soil heave is recorded and observable after completion of the first cycle of active and passive mode. It may also be observed the occurrence of sand disturbance, in particular in the soil region immediately above the inclusion (trapdoor). This means that the volume of soil above the trapdoor was increased resulting in an imminent reduction in the sand density and shear strength. Despite conduction of further cycles of active and passive modes, surface settlement was comparative downward displacement indicating that no further significant change in the volume of the sand bed was evident which means that the shear strength of the sand remained relatively stable. This can be confirmed by the closure $\mathrm{k}$ values during active and passive arching as well as the improved steadiness of $k$ values in Figure 4. The results, therefore, suggest that cycles of yielding and the rise of inclusion exacerbate the formation of active and passive arches causing significant changes to the load transfer on the inclusion in particular during the first cycle. This could be attributed to i. 
localisation of deformation along the same slip planes and causing shear bands as implied from the physical observations taken during the tests ii. Shearing of the soil mass during the first cycle reducing the shear resistance along the slip planes and iii. Permanent change in the vertical stress from the previous arching mode. The volume change of sand during shearing leads to dilation or contraction of the soil and hence change in density which affects the sand shear strength. Zhang et al. (2011) observed that dilation leads to significant volume change and consists of reversible and irreversible components. The later was found to gradually increase with continued shearing whereas the reversible dilation depends upon the shearing direction. As a result, change in the angle of friction is imminent due to dilatancy of the soil mass which is influenced by the shearing direction.

Figure 6 presents the results of sequential active and passive modes on a sample of dense sand with a height of $100 \mathrm{~mm}$ over different ranges of inclusion displacements of $2 \%, 10 \%$ and $20 \%$. All three tests were started with yielding of the inclusion to a predetermined displacement to develop an initial active arching followed by reversing the movement so that the sand bed was in a passive mode. A number of cycles of active and passive mode were then performed over the predetermined displacement ranges. It can be seen that irrespective of the yielding displacement, the normalised load relations followed the same load-deformation path for the monotonic active mode. The recorded normalised load on the inclusion is dependent on the magnitude of displacement prior to reaching the relatively stable load which was measured to be around $5 \%$ normalised displacement. On reversing the displacement direction for the sand bed to be in the passive mode, different paths were followed up to reaching a maximum pressure on the inclusion of $180 \%$. Subsequent cycles of active and passive arching followed the same paths as those for the second cycle which were consistent with previously discussed results in Figure 3 . The data suggest that hysteresis in the relationship between normalised load and normalised displacement exists and is dependent on the

332 displacement and route followed.

\subsection{Effect of burial height}


For the fourth series of experiments, samples of sand beds with different heights were examined to investigate the effect of sand height on sequential active and passive arching. Results of tests with sand bed heights of $0.50 \mathrm{~B}, 1.0 \mathrm{~B}, 2.0 \mathrm{~B}, 3.0 \mathrm{~B}, 4.0 \mathrm{~B}$ and $5.0 \mathrm{~B}$ where $\mathrm{B}$ is the width of the yielding inclusion (trapdoor) were presented in Figures 7 and 8.

Figure 7 shows the normalised load during the initial yielding of the trapdoor. It is clear that increasing the height of the sand bed leads to a substantial reduction in the load on the inclusion because of the formation of a full and deep arch. The results are in agreement with those reported in previous studies (e.g.; Terzaghi 1936; McNulty 1965; Ladanyi \& Hoyaux 1969; Adachi et al. 1997 \& Iglesia et al. 2014). The data in Fig 7 also illustrate that with the increase in sand height, the relative change in normalised load with increasing yield displacement reduced greatly. This could be attributed to formation of a virtually stable arch which would be the case for deeply buried underground inclusions.

Results for full cycles of active and passive modes are presented in Figure 8. Data for the passive mode when the direction of movement was reversed to initiate passive mode showed different features as a function of sand bed height. For shallow heights up to $\mathrm{H} / \mathrm{B}=2.0$, the normalised load responded quickly to the upward displacement leading to a rapid increase in the measured load. 100 $\%$ normalised load was observed to be reached within $1.5 \%$ of normalised displacement. However, with increasing the burial height, a large movement in the range of $4 \%$ was required to reach $100 \%$ normalised load. This could be attributed to the formation of a full arch in the case of high burial depths leading to significant dilation of the soil region immediately above the inclusion during the previous yielding and to the requirement for a large displacement to compress the soil under the arch prior to the transfer of load to the soil mass in the passive mode. In other words, small burial heights are only able to result in partial formation of active arching. Costa et al. 2009 noted that the behaviour of active arching of soil with shallow heights $((\mathrm{H} / \mathrm{B}) \leq 2)$ is different from the behaviour of active arching of soil with deep heights $((H / B) \geq 2)$ which is in agreement with the results presented above. 
The maximum normalised load on the passive mode is directly related to the burial depth. The data illustrate that despite the increase in the number of cycles, the normalized load was relatively constant regardless of the burial height of the soil as shown in Figure 8. To enhance the discussion, surface settlement is plotted against the normalised soil height after the first and tenth cycles of sequential active and passive arching as demonstrated in Figure 9. A significant reduction in the measured settlement is experienced when the burial height increases beyond a normalised height of 2.50. Van Eekelen et al. (2003)'s study showed that shallow burial heights were not able to mobilize shear stress noticeably and the development of soil arching was incomplete. The data suggest that the critical height that is often considered to be the height at which the settlement is equal to zero, is between a normalised height of 2 3. Under repeated sequential active and passive arching cycles, surface settlement started to appear and increased with the number of cycles. No critical height could be confirmed after ten cycles of active and passive arching due to increased surface settlement as the surface settlement was recorded to be $4.0 \mathrm{~mm}$ after ten cycles. This means that the critical height was not only dependent on the burial height but also on the number of active and passive cycles, which is in line with the previous observation of a weakened arching mechanism under cyclic alterations of active and passive resistance.

In addition, the stress reduction ratio (SRR) is determined by dividing the vertical load on the trapdoor by the initial at rest overburden pressure during the active mode under repeated sequential active and passive arching. If the SRR is equal to zero this means that all load was transferred to the fixed sides (full arching). When SRR is equal to one this means that no arching is developed (Low et al. 1994). SRR provides a useful illustration of the effect of cycle number on the maximum arching of soil:

$$
S R R=\frac{\sigma_{v}}{\gamma H}
$$

where; $\sigma_{v}$ is the vertical pressure on the trap door, $\gamma$ is the soil unit weight and $H$ is the height of the soil bed. Figure 10 presents the results of the Stress reduction ratio (SRR) with the number of cycles for different heights of soil under repeated sequential active and passive arching. It can be seen that 
most of load increase occurs in the second cycle in comparison with loads measured during the first cycle. This means that arching in soil is substantially decreased during the first few active and passive cycles irrespective of the sand bed height. Increasing bed height has a minor influence on the stress reduction ratio. A slight effect was noted with further alteration of active and passive cycles due to weakened arches. Minor reliance was also observed on the burial height as shown in Figure 10.

\section{CONCLUSIONS}

A comprehensive laboratory investigation was conducted to explore the effects of sequential active and passive arching on the load transfer and re-distribution of stresses using the well-known trapdoor test. The following conclusions can be drawn from the presented results and discussion:

1. Despite attainment of classical relationships for the normalised load during monotonic active and passive modes, a significant change on the redistribution of loads occurs under sequentially alteration of active and passive resistance. This highlights that relying on maximum resistance and minimum loads on the inclusion as a result of complete passive and active arching respectively seems to be unsustainable and requires special care.

2. The results suggested that substantial weakening of soil arching occurs during the second cycle of active and passive arching onwards. This could be attributed to i. localisation of deformation along the same slip planes, causing slip bands, ii. Shearing of the soil mass during the first cycle reducing the shear resistance along the slip planes and iii. Permanent change in the vertical stress from the previous arching mode, whether active or passive.

3. The lateral earth pressure coefficient is a good analogue reflecting changes of principal stress during active and passive modes. It is clear that the suggested value of $k=1.0$ by Terzaghi 1943 is still appropriate for sedimentary granular materials at large displacement. Likewise, a value of $k=0.25$ would appear to be reasonable for passive resistance during the passive mode. 
4. Increasing the displacement of the yielding inclusion had a limited effect on redistribution of the loads and soil arching due to reaching the ultimate state.

5. The load on the inclusion is dependent on the magnitude of displacement prior to reaching the relatively stable load. The data suggest that hysteresis in the relationship between normalised load and normalised displacement exists and is dependent on the displacement and route followed. Different paths are followed up to reaching maximum or minimum pressure on the inclusion.

6. The critical height was affected significantly under repeated conditions of active and passive modes due to the collapse and/or reduction of soil arching.

7. The results suggested that dilation of the soil improves with increasing burial height as a result of formation of full arching and leading to lower loads on the inclusion during yielding, improving the capacity to absorb upward displacement during the passive mode. 
Adachi, T., Kimura, M., Nishimura, T., Koya, N., \& Kosaka, K. 1997. Trap door experiment under centrifugal conditions. Deformation and Progressive Failure in Geomechnics, IS-Nagoya'97, pp.725-730.

BSI (British Standards Institution) 1990. BS 1377:1990. Methods of test for soils for civil engineering purposes-Part 2: Classification tests. London: British Standards Institution.

BSI (British Standards Instituation) 2004. BS EN ISO 14688 - 2:2004 Geotechnical investigation testing Identification and classification of soil, Part 2: Principles for a classification of soil

Chevalier, B., Combe, G., \& Villard, P. 2008. Experimental and numerical studies of load transfers and arching effect. In Proc., 12th Int. Conf. of the Int. Association for Computer and Advances in Geomechanics (IACMAG), Goa, India (pp. 273-280). Tucson, AZ: IACMAG.

Chevalier, B., Combe, G., \& Villard, P. 2009. Experimental and numerical study of the response of granular layer in the trap-door problem. Powders and Grains 2009: Proc., 6th Int. Conf. on the Micromechanics of Granular Media, M. Nakagawa and S. Luding, eds., American Institute of Physics, Melville, NY, 649-652

Chevalier, B., Combe, G., Villard, P. 2012. Experimental and discrete element modeling studies of the trapdoor problem: influence of the macro-mechanical frictional parameters. Acta Geotechnica, 7(1), pp.15-39.

Clark, C. M. 1971. Expansive-soil effect on buried pipe. Journal-American Water Works Association. 1971 Jul $1 ; 63(7): 424-7$

Costa, Y. D., Zornberg, J. G., Bueno, B. S., \& Costa, C. L. 2009. Failure mechanisms in sand over a deep active trapdoor. Journal of Geotechnical and Geoenvironmental Engineering. 2009 Apr 27;135(11):1741-53.

Cui, Z. D., Yuan, Q., \& Yang, J. Q. 2017. Laboratory model tests about the sand embankment supported by piles with a cap beam. Geomechanics and Geoengineering, pp.1-13.

Dalvi, R. S., \& Pise, P. J. 2012. Analysis of arching in soil-passive state. Indian Geotechnical Journal, 42(2), pp.106-112

Dewoolkar, M.M., Santichaianant. K., \& Ko, H.Y. 2007. Centrifuge modeling of granular soil response over active circular trapdoors. Soils and foundations. 2007;47(5):931-45.

Evans, C. H. 1983. An examination of arching in granular soils. S.M. thesis, Dept. of Civil Engineering, MIT, Cambridge, MA.

Fattah, M.Y., Mohammed, H. A., \& Hassan, H. A. 2016. Load transfer and arching analysis in reinforced embankment. Proceedings of the Institution of Civil Engineers-Structures and Buildings, 169(11), pp.797-808.

Gaoxiao, H., Quanmei, G., \& Shunhua, Z. 2011. Mechanical analysis of soil arching under dynamic loads. In Pan-Am CGS Geotechnical Conference.

Handy, R. L. 1985. The arch in soil arching. Journal of Geotechnical Engineering, 111(3), 302-318.

Horgan, G. J., \& Sarsby, R. W. 2002. The arching effect of soils over voids and piles incorporating geosynthetic reinforcement. Geosynthetics - 7th ICG - Delmas, Gourc and Girard (eds), Swets \& Zeitlinger, Lisse ISBN 905809523 1, pp. 373-378.

Iglesia, G. R., Einstein, H. H., \& Whitman, R. V. 1999. Determination of vertical loading on underground structures based on an arching evolution concept. Proceedings 3rd National Conference on Geo-Engineering for Underground Facilities, pp. 495-506.

Iglesia, G. R., Einstein, H. H., \& Whitman, R. V. 2014. Investigation of soil arching with centrifuge tests. Journal of Geotechnical and Geoenvironmental engineering. 140(2).

Jenck, O., Combe, G., Emeriault, F., \& De Pasquale, A, (2014). January. Arching effect in a granular soil subjected to monotonic or cyclic loading: kinematic analysis. In C. Gaudin and D. White eds., 8th international conference on physical modelling in Geotechnics

Koutsabeloulis, N. C., \& Griffiths, D. V. (1989). Numerical modelling of the trap door problem. Geotechnique, 39(1), pp.77-89. 
Krynine, D. P. (1945). Discussion of "Stability and stiffness of cellular cofferdams," by Karl Terzaghi, Transactions, ASCE, Vol. 110, pp. 1175- 1178.

Ladanyi, B., \& Hoyaux, B. (1969). A study of the trap-door problem in a granular mass. Canadian Geotechnical Journal, 6(1), pp.1-14.

Lambe, T. W., \& Whitman, R. V. (1969). Soil Mechanics, 553 pp. Jhon Wiley \& Sons, N. York.

Lee, C. J., Wu, B. R., Chen, H. T., \& Chiang, K. H. (2006). Tunnel stability and arching effects during tunneling in soft clayey soil. Tunnelling and Underground Space Technology, 21(2), pp.119132.

Low, B.K., Tang, S.K., \& Choa ,V. (1994). Arching in piled embankments. ASCE J Geotech Eng 120(11):1917-1938

McNulty, J. W. (1965). An experimental study of arching in sand (No. AEWES-TR-1-674). ARMY ENGINEER WATERWAYS EXPERIMENT STATION VICKSBURG MS.

Moradi, G., Bonab, M. H., \& Abbasnejad, A. (2015). Experimental Modeling and Measuring Stresses and Strains during Arching Phenomenon. Geosciences, 5(2), pp.53-61.

Meguid, M.A., Saada, O., Nunes, M. A., \& Mattar, J. (2008). "Physical Modeling of Tunnels in Soft Ground: A Review," Tunn. Undergr. Sp. Tech, Vol. 23, No. 2, pp. 185-198.

Pardo, G. S., \& Sáez, E. (2014). Experimental and numerical study of arching soil effect in coarse sand. Computers and Geotechnics, 57, pp.75-84

Pirapakaran, K., \& Sivakugan, N. ( 2007a). "A laboratory model to study arching within a hydraulic fill stope." Geotech. Test. J., 30(6), 496-503.

Pirapakaran, K., \& Sivakugan, N. (2007b). "Arching within hydraulic fill stopes." Geotech. Geologic. Eng., 25(1), 25-35.

Potts,V. J., \& Zdravkovic, L. (2008). Finite element analysis of arching behaviour in soils. The 12th International Conference of International Association for Computer Methods and Advances in Geomechanics (IACMAG), Goa, India, October, 2008, pp. 3642-3649.

Russell, D., Naughton, P. J., \& Kempton, G. (2003). 'A new design procedure for piled embankments', In: Proceedings of the 56th Canadian Geotechnical Conference and 2003 NAGS Conference, pp. 858-865.

Russell, D., \& Pierpoint, N. (1997). 'An assessment of design methods for piled embankments', Ground Engineering, 30(10), pp. 39-44 .

Sadrekarimi, J., \& Abbasnejad, A. (2008). An experimental investigation into the arching effect in fine sand. International Journal of Engineering-Transactions B: Applications, 21(4), pp.345360.

Stone, K. J. L. (1988). "Modelling of rupture development in soils." Ph.D. Dissertation, Wolfson College, Cambridge Univ., Cambridge, U.K

Stone, K. J. L., \& Muir Wood, D. (1992). "Effects of dilatancy and particle size observed in model tests on sand." Soils Found., 32(4),43-57.

Tanaka, T., \& Sakai, T. (1993). progressive failure and scale effect of trap-door problems with granular materials. soils and foundations, 33(1), pp.11-22.

Terzaghi, K. (1936). 'Stress distribution in dry and in saturated sand above a yielding trapdoor', Proceeding of the International Conference on Soil Mechanics and Foundation Engineering Bd.1. Cambrigde, pp. 307-311.

Terzaghi, K. (1943). 'Theoretical Soil Mechanics', John Wiley and Sons, New York.

Van Eekelen, S. J., Bezuijen, A., \& Oung, O. (2003). Arching in piled embankments; experiments and design calculations. Proceedings of Foundations: Innovations, observations, design and practice. 2003 Sep:885-94.

Van Eekelen , S. J. M. (2015). Basal Reinforced Piled Embankments. Experiments, field studies and the development and validation of a new analytical design model (Doctoral dissertation, PhD thesis, Delft University of Technology).

Vardoulakis, I., Graf, B., \& Gudehus, G. (1981). Trap-door problem with dry sand: a statical approach based upon model test kinematics. Int J Num Anal Methods Geomech 5:57-78 
534

535

536

537

538

539

540

541

542

543

544

545

546

547

548

549

550

551

552

553

554

555

556

557

Villard, P., Gourc, J. P., \& Giraud, H. (2000). A geosynthetic reinforcement solution to prevent the formation of localized sinkholes. Canadian Geotechnical Journal, 37(5), 987-999.

Wang, L., Leshchinsky, B., Evans, T. M., \& Xie, Y. (2017). Active and passive arching stresses in $c^{\prime}-\phi^{\prime}$ soils: A sensitivity study using computational limit analysis. Computers and Geotechnics, 84, 47-57.

Zhang, G., Wang, L. and Zhang, L.M. (2011). Dilatancy of the interface between a structure and gravelly soil. Géotechnique 61(1):75-84. 
Table 1. Properties of sand used in this study

\begin{tabular}{lc}
\hline Parameter & Value \\
\hline $\mathrm{d}_{10}(\mu \mathrm{m})$ & 570 \\
$\mathrm{~d}_{30}(\mu \mathrm{m})$ & 630 \\
$\mathrm{~d}_{50}(\mu \mathrm{m})$ & 690 \\
$\mathrm{~d}_{60}(\mu \mathrm{m})$ & 710 \\
Uniformity coefficient $\left(\mathrm{c}_{\mathrm{u}}\right)$ & 1.25 \\
Coefficient of curvature $\left(\mathrm{c}_{\mathrm{c}}\right)$ & 0.98 \\
Maximum dry Unit weight $\left(\mathrm{kN} / \mathrm{m}^{3}\right)$ & 16.50 \\
Optimum water content $(\%)$ & 8.0 \\
Angle of friction $(\phi)$ & $33^{\circ}$ \\
\hline
\end{tabular}

560

561 
Table 2. Measured dry unit weight at different heights

\begin{tabular}{lcccccc}
\hline $\begin{array}{l}\text { Thickness of } \\
\text { sand bed } \\
(\mathrm{mm})\end{array}$ & 0 & 100 & 200 & 300 & 400 & $\begin{array}{c}\text { Average dry } \\
\text { unit weight } \\
\left(\mathrm{kN} / \mathrm{m}^{3}\right)\end{array}$ \\
\cline { 2 - 6 } & 16.36 & & & & & 16.36 \\
50 & 16.36 & & & & & 16.36 \\
100 & 16.38 & 16.36 & & & & 16.37 \\
200 & 16.40 & 16.41 & 16.35 & & & 16.38 \\
300 & 16.42 & 16.41 & 16.38 & 16.33 & & 16.39 \\
400 & 16.42 & 16.41 & 16.40 & 16.36 & 16.32 & 16.39 \\
500 & & & & & & \\
\hline
\end{tabular}

564

565 
Table 3. Summary of experimental programme

\begin{tabular}{|c|c|c|c|}
\hline Series & $\begin{array}{l}\text { Number } \\
\text { of tests }\end{array}$ & Variable parameters & Fixed parameters \\
\hline 1 & 2 & $\begin{array}{l}\text { monotonic active and } \\
\text { passive arching }\end{array}$ & $\begin{array}{c}H=100 \mathrm{~mm} \\
B=100 \mathrm{~mm} \\
d=10 \mathrm{~mm}\end{array}$ \\
\hline II & 2 & $\begin{array}{l}\text { initial active mode and } \\
\text { initial passive mode }\end{array}$ & $\begin{array}{c}H=100 \mathrm{~mm} \\
B=100 \mathrm{~mm} \\
d=10 \mathrm{~mm} \\
n=5\end{array}$ \\
\hline III & 3 & $\begin{array}{c}\text { Normalised displacement } \\
2,10,20 \%\end{array}$ & $\begin{array}{c}H=100 \mathrm{~mm} \\
B=100 \mathrm{~mm} \\
\text { active \& passive } \\
\quad n=10\end{array}$ \\
\hline IV & 6 & $\begin{array}{c}H=0.5 B, 1 B, 2 B, 3 B, 4 B \\
5 B\end{array}$ & $\begin{array}{c}\quad d=10 \mathrm{~mm} \\
B=100 \mathrm{~mm} \\
\text { active } \& \text { passive } \\
n=5\end{array}$ \\
\hline
\end{tabular}

568

$H=$ Thickness of sand bed, $d=$ Trapdoor displacement, $B=$ Trapdoor width and $n=$ number of

569 cycles 


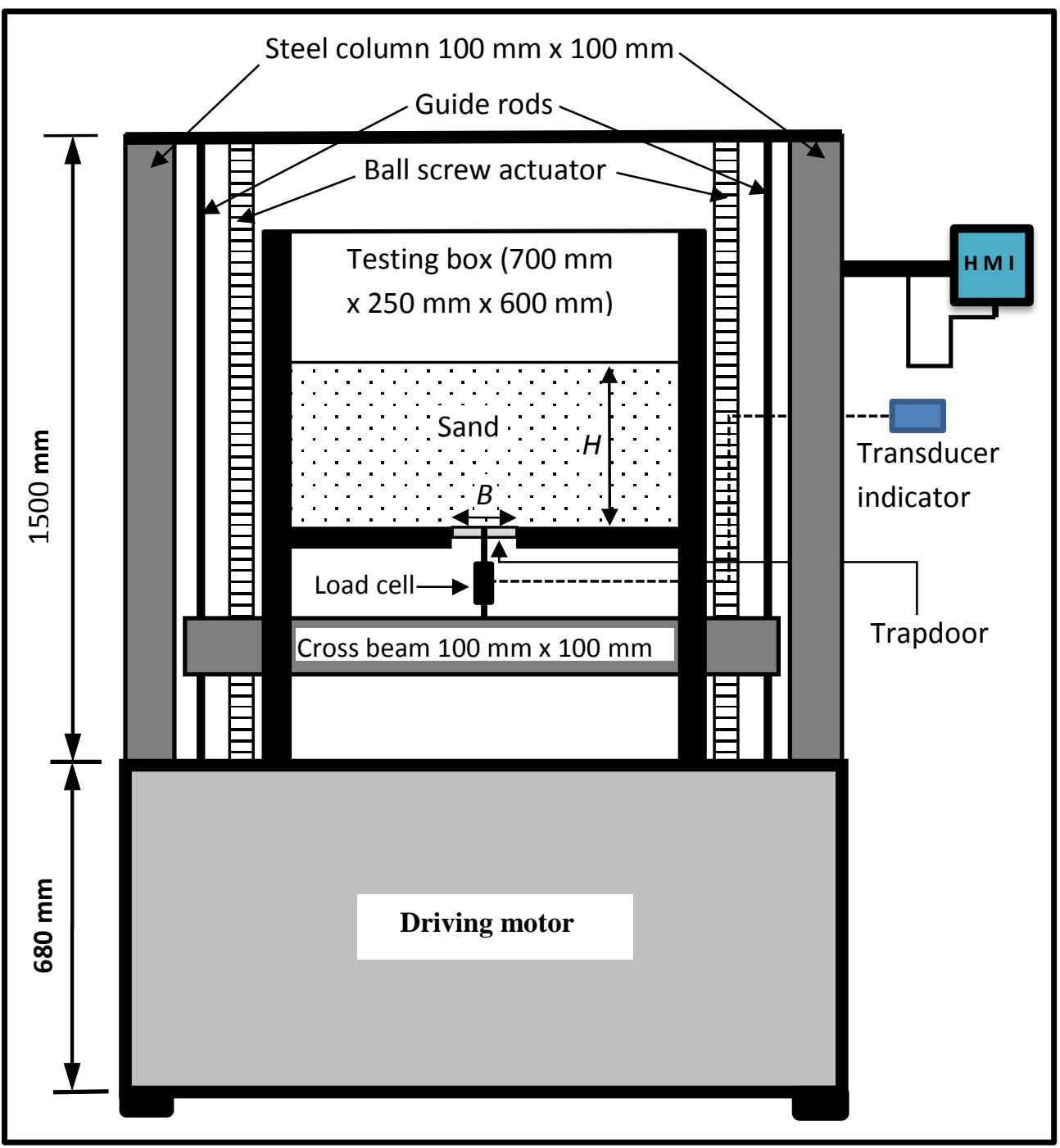

589

590 


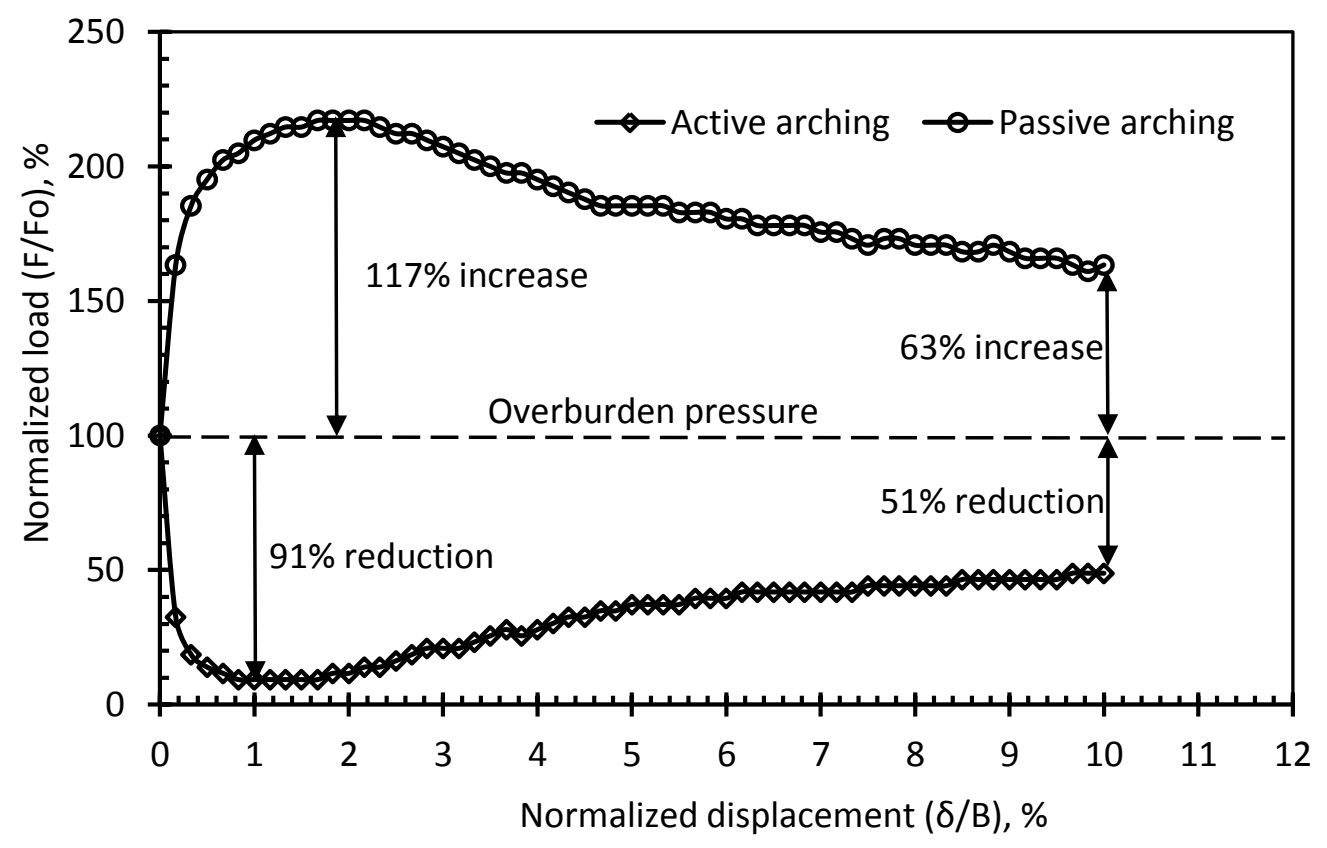

600

Figure 2: Normalised load versus normalised displacement during monotonic active and passive 602 arching

603 


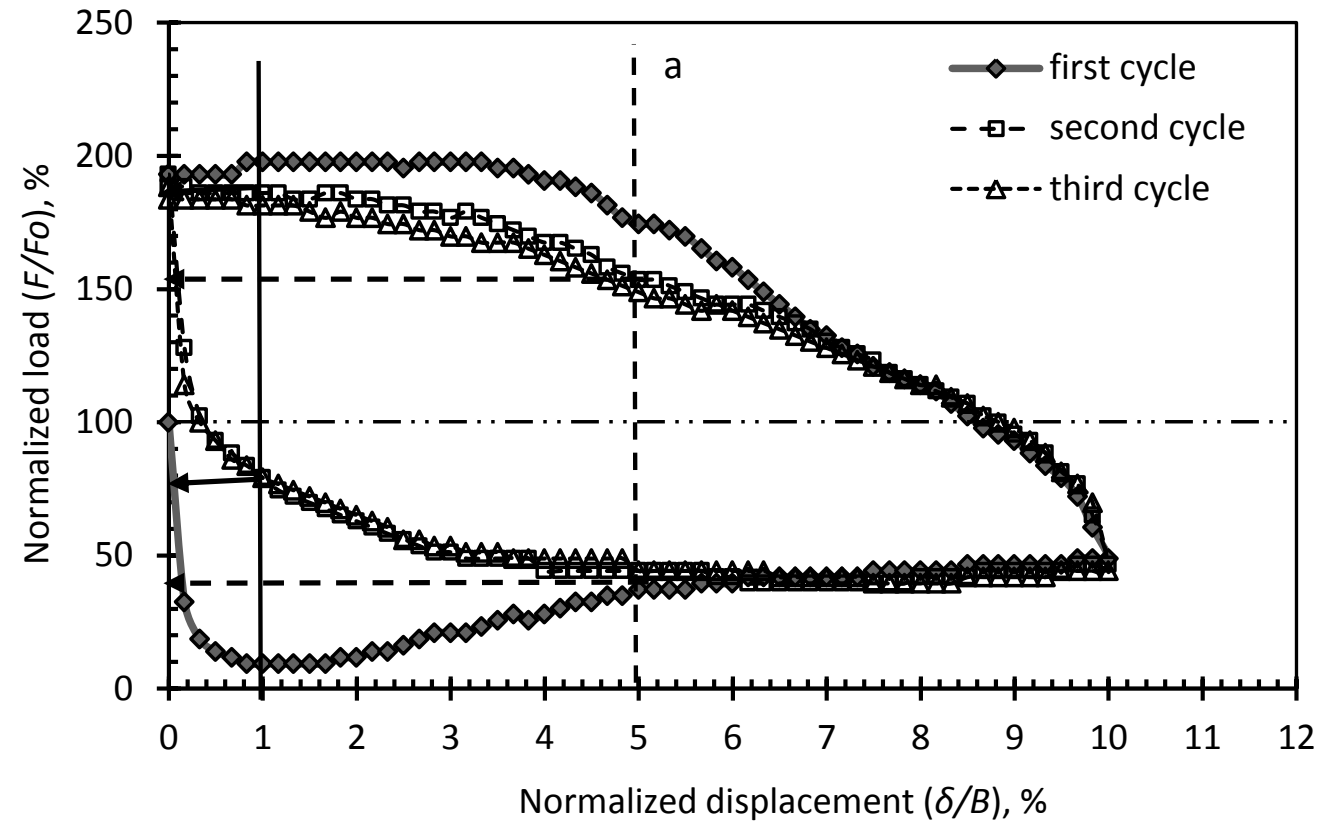

604

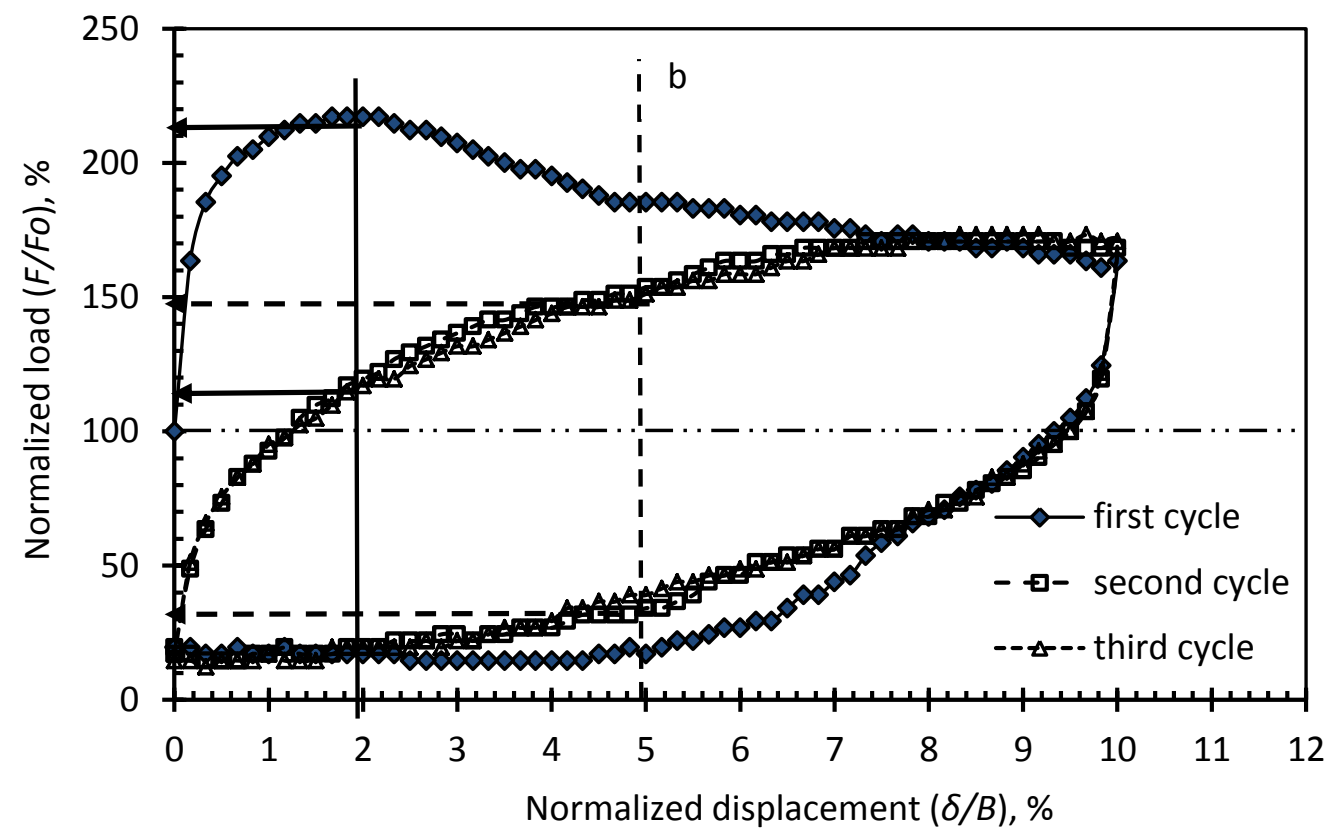

Fig. 3: Normalised load versus normalised displacement during a. sequential active and passive 607 arching and $\mathrm{b}$. sequential passive and active arching 


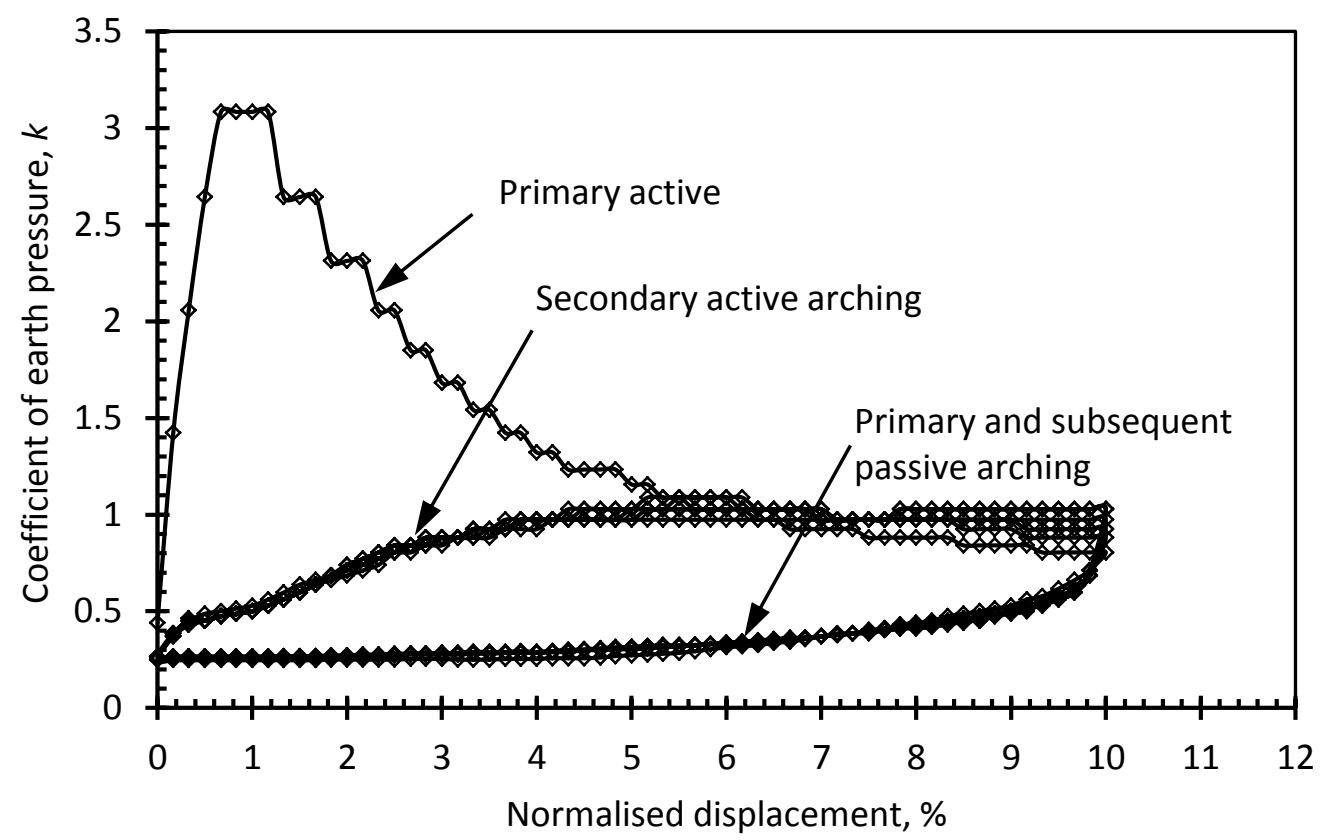

Figure 4: Coefficient of lateral earth pressure as a function of normalised displacement during 

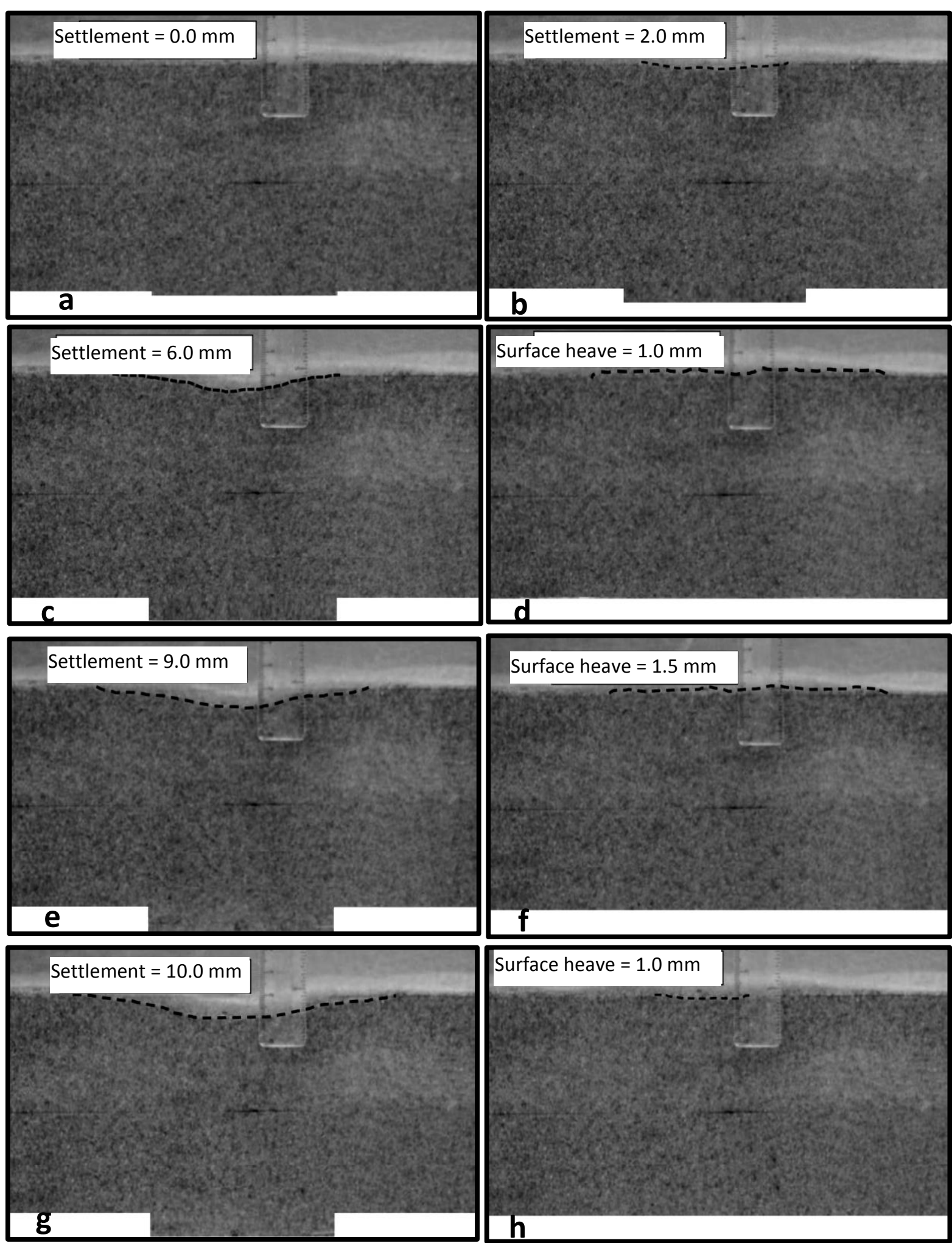

Surface heave $=1.0 \mathrm{~mm}$

Figure 5: Evolving of surface deformation during sequential active and passive arching

a. Active arching at normalised displacement of $2 \%$, b. Active arching at normalised displacement of $5 \%$, c. Active arching at normalised displacement $10 \%$, d. Passive arching at normalised displacement of $10 \%$, e. Second cycle of active arching at normalised displacement $10 \%$, $\mathrm{f}$. Second cycle of passive arching at normalised displacement of $10 \%$ g. Tenth cycle of active arching at normalised displacement $10 \%$ and $\mathrm{h}$. Tenth cycle of passive arching at normalised displacement of $10 \%$. 


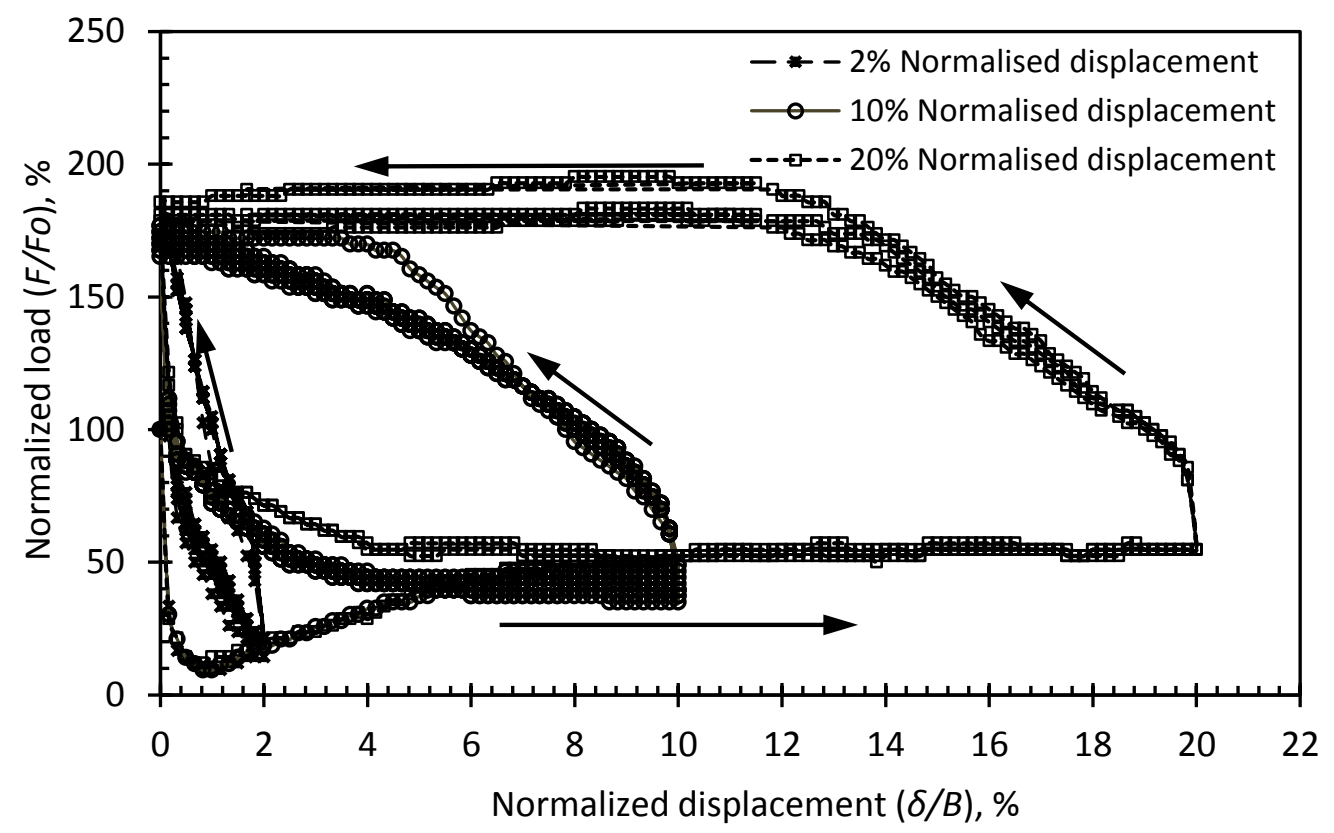

645

Figure 6: Relationships between normalised load and normalised displacement from cycles performed at different normalised displacement

648

649

650

651

652 


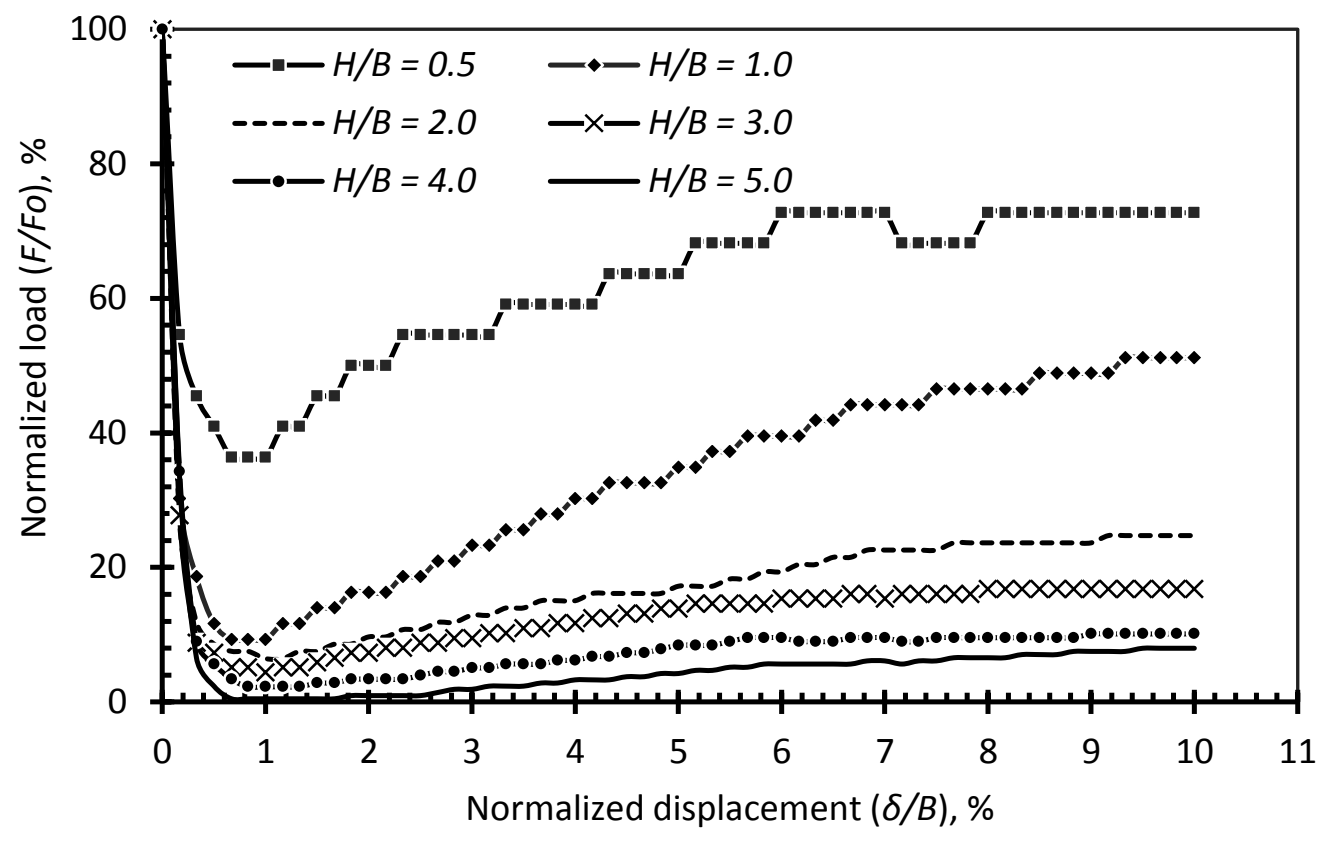

Figure 7: Normalised load versus normalised displacement during initial active arching as a function of bed height. 


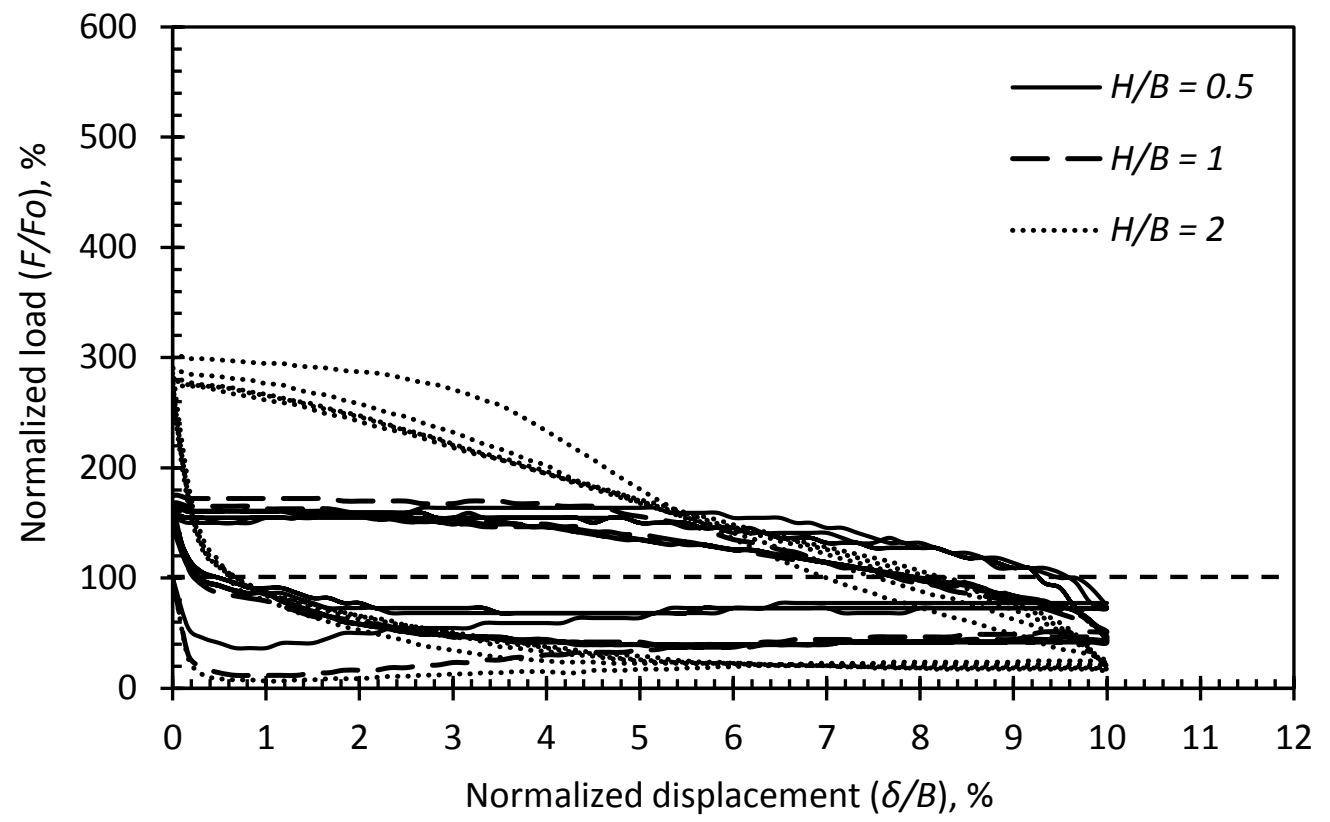

666

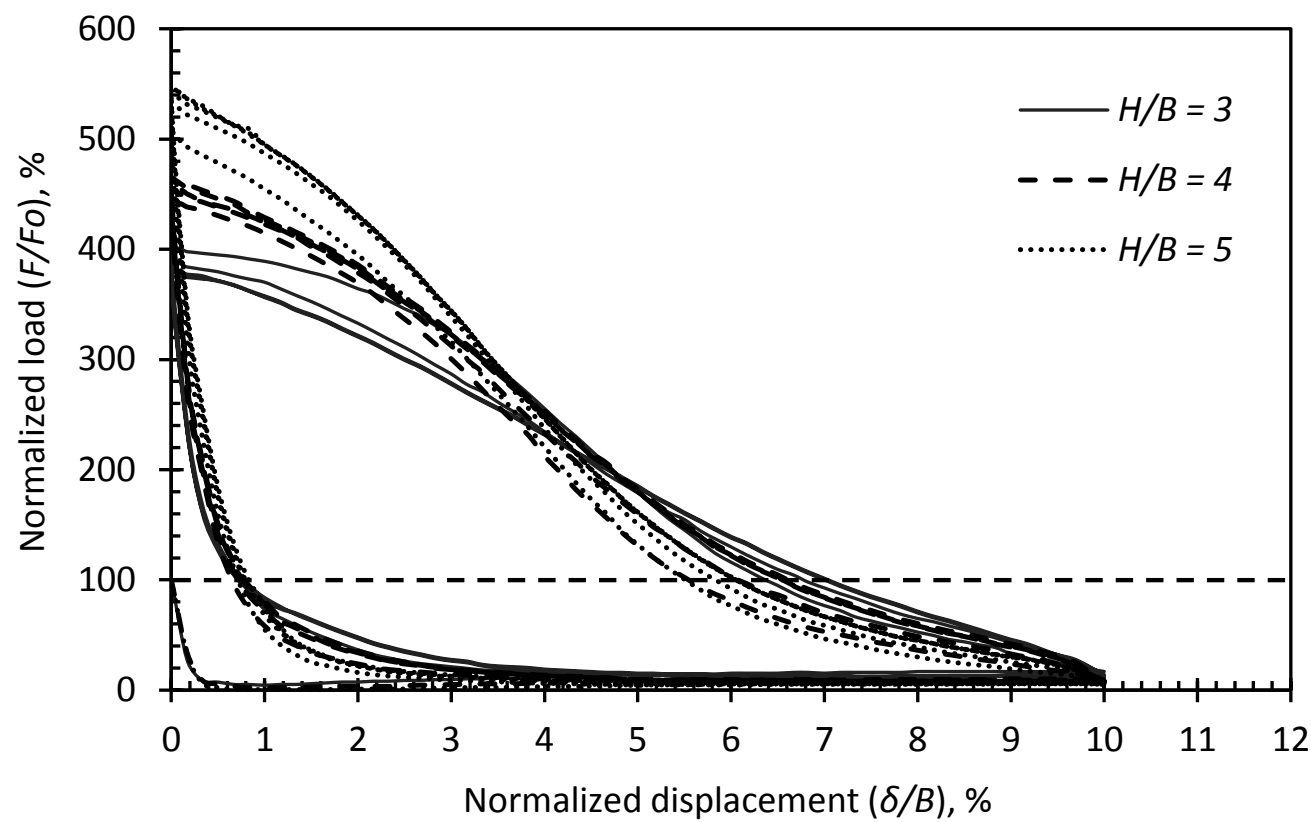

667

Figure 8: Normalised load versus normalised displacement during sequential active and passive arching

670

671 


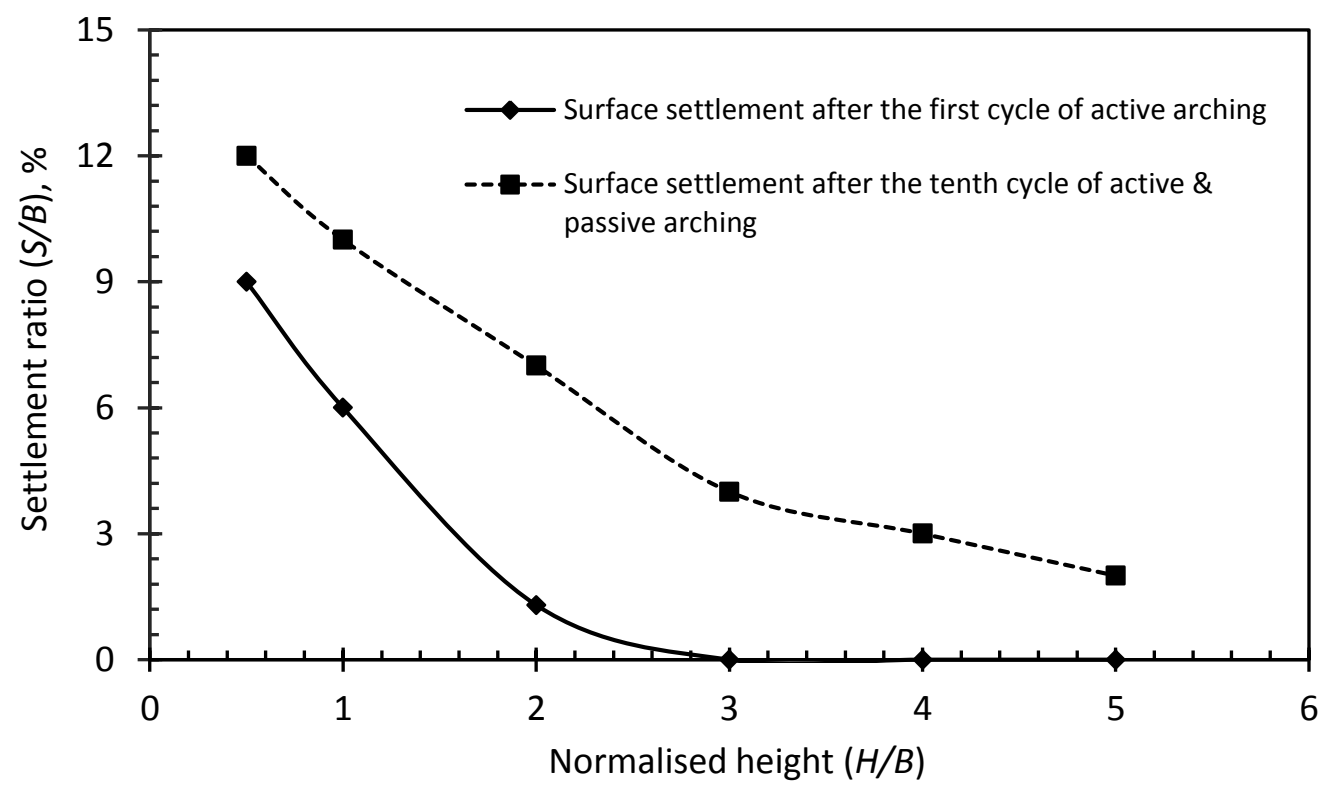

674 


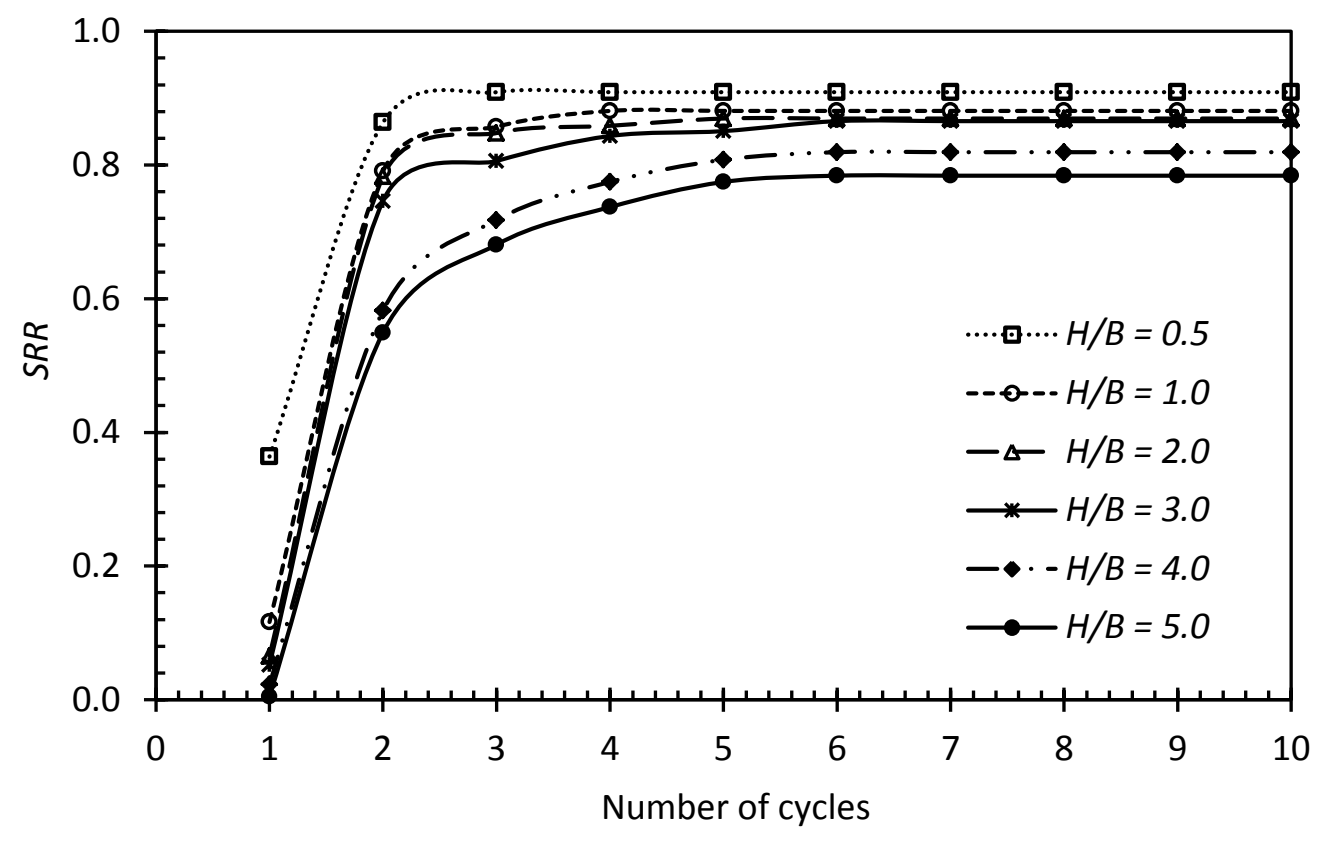

680

Figure 10: Stress reduction ratio versus cycle number of active and passive arching at $1 \%$ normalised 682 displacement for various normalised heights. 